\title{
Cem anos de invenção e matemática em Armin Hofmann
}

\section{A hundred years of invention and mathematics in Armin Hofmann}

\author{
Alice Viggiani, Universidade de São Paulo. \\ alice.viggiani@usp.br \\ Clice Mazzilli, Universidade de São Paulo \\ clice@usp.br
}

\section{Resumo}

Junho de 2020 foi o mês do centenário do professor e designer gráfico Armin Hofmann. Um dos fundadores da Escola de Design da Basileia, o suíço defende o ensino a partir da criatividade e do desenho como forma de pesquisa e investigação, ao mesmo tempo que tem como marca de sua prática profissional o estilo intuitivo, mas de rigor construtivo claro e conciso. A partir da análise de sua obra-chave, o Graphic Design Manual: Principles and Practice (1965), dos relatos de Dorothea Hofmann em seu livro sobre o modelo educacional da Basileia e da entrevista com o professor e designer brasileiro contemporâneo Leopoldo Leal, o artigo busca entender de que forma a escola moderna de design gráfico dos anos 1950 e 1960, o ensino da Basileia e a atuação de Armin Hofmann ecoam nos dias de hoje no ensino de design no Brasil.

Palavras-chave: Armin Hofmann, Processo criativo, Design gráfico.

\begin{abstract}
June 2020 marks the birth centenary of Swiss professor and graphic designer Armin Hofmann. One of the founders of The Basel School of Design, Hofmann advocates teaching based on creativity and on the use of drawing as a tool for researching and investigating, while, at the same time, his professional practice identity follows an intuitive style, but with a clear and concise constructive rigor. Based on the analysis of his key work, Graphic Design Manual: Principles and Practice (1965), on the accounts of Dorothea Hofmann extracted from her book about the Basel education model, and on the interview with Brazilian professor and contemporary designer Leopoldo Leal, this article seeks to understand how the graphic design modern school from the 1950s and 1960s, the Basel education model, and Armin Hofmann's practice are still echoing in the design education in Brazil.
\end{abstract}

Keywords: Armin Hofmann, Creative Process, Graphic Design. 


\section{Introdução}

Em junho de 2020, Armin Hofmann completou cem anos de vida. Um dos fundadores da Escola de Design da Basileia, o designer gráfico e professor suíço é considerado um dos pioneiros do assim denominado Estilo Tipográfico Internacional, escola das décadas de 1950 e 1960, conhecida pelo rigor construtivo, racionalidade e concisão. Hofmann defendia o ensino a partir da criatividade e do desenho como forma de pesquisa e investigação. Seus ensinamentos e a influência de sua prática profissional repercutem até os dias de hoje, seja direta ou indiretamente, tanto no quadro internacional como no Brasil.

A extensa atuação de Hofmann, tanto no campo profissional como na experiência de ensino, foram por ele sintetizados em sua obra seminal Graphic Design Manual: Principles and Practice [Manual de design gráfico: princípios e prática], de 1965. O livro é um manual de cunho essencialmente didático, que reúne exercícios elaborados por Hofmann ao longo de seus anos como educador na Escola de Design Gráfico da Basileia (Schule für Gestaltung Basel), na Suíça. Segundo a definição do próprio autor, "[...] é uma tentativa de fornecer uma abordagem metódica aos problemas do design gráfico." (HOFMANN, A., 2015, p. 36, tradução nossa ${ }^{1}$ ). O documento expressa a complexidade que existiu no período moderno, delegando a favor da experimentação e inventividade sem, contudo, deixar de lado o rigor construtivo e a matemática das estruturas formais.

É essa mescla, essa apresentação simultânea de trabalhos profissionais com exercícios fundamentais didáticos, que faz do manual um documento à imagem e semelhança do próprio designer (e do próprio Estilo Tipográfico Internacional), que sempre teve a intenção não só de produzir, mas também de contar sua história e refletir sobre sua própria produção. O que o presente trabalho procura responder é como esse caráter ambivalente, de pensar campo profissional e ensino em conjunto, repercute nos dias de hoje e, mais especificamente, quais são os ecos dos postulados de Armin Hofmann no ensino nacional de design. Para tanto, foi realizada uma entrevista com o professor e designer Leopoldo Leal, que tem como mote de pesquisa os processos de criação em design gráfico. Além disso, foi feita uma leitura dos relatos de Dorothea Hofmann, ex-aluna da Basileia, bem como se examinou o manual de Armin Hofmann, dissecando os exemplos dados e ordenando-os em novas categorias.

Passar o carvão pesadamente sobre um papel apoiado em uma planta ou raspar o grafite em uma folha de papel sobre o asfalto e criar uma textura que será o padrão de fundo de um cartaz. À primeira vista, é difícil imaginar que tais ensinamentos estejam inseridos em um manual de design gráfico suíço dos anos 1960, ainda mais tendo este sido escrito por uma das figuras pioneiras da escola moderna de design. Armin Hofmann entendia que não existe trabalho educacional sem prática profissional e vice-versa: "A colaboração entre educadores e profissionais é, portanto, algo que está nas raízes de nossa existência.” (HOFMANN, A., 2015, p. 40).

\footnotetext{
${ }^{1}$ Esta e demais citações originalmente em língua estrangeira têm tradução nossa.
} 


\section{Armin Hofmann e a Escola da Basileia}

\section{A Suíça dos anos 1960}

Na segunda metade do século XX, o design gráfico suíço conseguiu causar uma grande agitação para além das fronteiras nacionais. Design Suíço e Estilo Suíço tornaram-se representativos de um design gráfico inovador de alta qualidade, que daria forma a toda uma época com seu amor pela precisão, objetividade e redução [...] (TRIEST VERLAG, 2016).

O cenário europeu após a Segunda Guerra Mundial é o da industrialização. A Suíça, particularmente, viu sua reputação internacional nas artes gráficas crescer e ganhar notoriedade a partir de seus cartazes, caracterizados "[...] pela competência, legibilidade, originalidade e simplicidade." (HOFMANN, D., 2016, p. 123). As empresas, a indústria e as instituições culturais também iriam adotar esse novo Estilo Suíço, pautado pelo rigor formal e pela economia do uso de elementos decorativos. A indústria publicitária veria seu florescimento vinculado principalmente ao modelo de ensino da Basileia principalmente (mas também de Zurique), com o surgimento de agências e, sobretudo, setores da indústria investindo em suas comunicações visuais, como é o caso da farmacêutica Geigy.

O modelo educacional da Gewerbeschule Allgemeine da Basileia, mais tarde conhecida como Escola de Design da Basileia, foi um importante pioneiro que levou ao avanço internacional do novo design gráfico suíço. Visões rígidas, embora não dogmáticas, aliadas a uma pragmática atitude em relação a questões de projeto, audácia experimental e claro compromisso com o modernismo desencadearam um amplo movimento de design gráfico, que se estenderia da Basileia para a Europa e os EUA. (TRIEST VERLAG, 2016).

Segundo Dorothea Hofmann, artista plástica e professora de desenho, esse Estilo Suíço em desenvolvimento deu-se muito por conta da introdução de aulas de artes gráficas nas escolas de artes e artesanato nesse período, o que acarretou "[...] um novo perfil profissional para os designers gráficos.” (HOFMANN, D., 2016, p. 120).

\section{O curso de design gráfico da Basileia}

A Escola da Basileia foi fundada no século XVIII, junto com as primeiras escolas de desenho, sob o nome Allgemeine Gewerbeschule Basel [Escola de Formação Profissional Geral da Basileia]. O departamento de Design Gráfico, no curso de Kunstgewerbeschule [Artes e ofícios] foi fundado em 1915 e mais tarde se tornaria a Escola de Design Gráfico. Inicialmente, eram dez estudantes por turma em um curso de quatro anos. À época de sua fundação, já contava com os professores Emil Ruder e Armin Hofmann, o qual assumiria a disciplina de desenho. O curso era iniciado com exercícios de composição e os dois temas considerados essenciais para a educação visual eram os princípios básicos de desenho e sua importância para o ofício (HOFMANN, D., 2016).

Dorothea Hofmann é descrita pela designer April Greiman como "uma desenhista incrível" e conta que teve sua "[...] primeira e única aula de desenho com ela, felizmente [...]" (GREIMAN, 2010). Em seu livro, Die Geburt eines Stils: Der Eifluss des Basler Ausbildungsmodells auf die Schweizer Grafik [O nascimento de um estilo: o impacto do modelo educacional da Basileia sobre o estilo suíço], de 2016, Dorothea Hofmann conta todo o percurso da escola, desde sua fundação, suas influências e 
diálogos até tempos mais recentes. Sua narrativa explicita a importância, a partir de meados do século XX, da Escola da Basileia para a formulação e consolidação do Estilo Suíço, que iria transpor fronteiras e, posteriormente, ser denominado como Estilo Tipográfico Internacional.

Dorothea Hofmann narra uma história alternativa da Escola da Basileia em comparação com as historiografias mais reconhecidas, tendo como ponto de partida um olhar de dentro. Primeiro, como aluna das primeiras turmas; depois, pela perspectiva de educadora e até mesmo de esposa, a partir de 1953, de Armin Hofmann. Segundo a autora, diversos nomes relevantes para a consolidação da linguagem suíça são frequentemente esquecidos, como Ernst Keller, que segue a tradição do cartaz suíço, o fotógrafo Hans Finsler, sem o qual seria “" ...] impossível mostrar como surgiu o Design Suíço [...]", ou ainda Sophie Taeuber-Arp, Alfred Willimann, Hermann Eidenbenz e Nelly Rudin (HOFMANN, D., 2016, p. 12).

\section{Diferenças entre os ensinos da Basileia e de Zurique}

A outra escola da Suíça que estava formando designers naquele momento era a da cidade de Zurique. Apesar de sua produção ter tido maior repercussão no cenário internacional (principalmente em um período posterior), sua voz não era a dominante, e, dentro do cenário suíço, as escolas se diferenciavam em seus postulados. Para o historiador Richard Hollis (2006, p. 215), a Basileia "[...] não se restringia apenas a fontes grotescas. Isso se distinguia do aspecto doutrinário e uniforme do curso de Josef Müller-Brockmann.”. De um lado, os professores de Zurique apreciavam o rigor estrutural visual e os postulados formais já consolidados. Já o corpo docente da Basileia assumia um caráter mais experimental e permitia um processo criativo mais inventivo e livre de preceitos preestabelecidos (HOLLIS, 2006). Dorothea Hofmann também entende que não havia propriamente um movimento uníssono do Estilo Suíço, sendo que "[...] a pedagogia da Basileia e a direção construtiva-concreta de Zurique seguiram seus caminhos separados." (HOFMANN, D., 2016, p. 279).

\section{O ensino de Armin Hofmann}

Armin Hofmann começou a ministrar aulas na Basileia em 1947. Acreditava na criatividade e no desenho como ferramentas de pesquisa. Se Dorothea Hofmann (2016, p. 25) enxerga que desde o século XVIII, na Basileia, “[...] o desenho é considerado uma matéria elementar que ajuda os estudantes a desenvolver seu próprio julgamento [...]", Armin Hofmann, por sua vez, eleva ainda mais a importância conferida à linguagem: "É apenas no desenho, que ocupa posição desprivilegiada no currículo, que pensar, inventar, representar, transpor e abstrair podem ser correlacionados." (HOFMANN, A., 2015, p. 37). Em entrevista com Leopoldo Leal, é perceptível como a noção de desenho defendida ali por Hofmann encontra consonância com a visão do professor brasileiro:

Vejo o desenho como uma linguagem e também como uma ferramenta importante. É a maneira de você externalizar ideias. O desenho tem essa capacidade de nos permitir realizar, verificar, porque na nossa mente tudo é vago, mas quando jogamos para o desenho, 
verificamos se isso está do jeito que imaginávamos ou não, porque é um caminho muito longo da cabeça até o papel. (informação verbal) ${ }^{2}$.

"A história da literatura é estudada, mas o mundo imaginário do aluno e seus poderes de autoexpressão não podem se desenvolver adequadamente.” (HOFMANN, A., 2015, p. 37). O designer, ao analisar o ensino tradicional, entende que enquanto na educação infantil existe uma abordagem criativa, que acontece no campo da experiência e do sensorial, a criatividade e o desenho vão sendo desconsiderados como ferramenta de ensino conforme os anos escolares vão avançando. Isso, talvez, por influência de fatores externos, em que prevalece a acumulação rápida e fácil de conhecimento. Assim, as faculdades de artes aplicadas "[...] ficam com um legado de problemas quase insolúveis [e] precisam lidar com essa defasagem da base de pensamento dos estudantes." (HOFMANN, A., 2015, p. 37). Leopoldo Leal, mais de meio século depois, no Brasil, ainda observa essa quebra entre ensino infantil e posterior:

Essa ruptura do jardim da infância para primeiro, segundo ano é muito grande. No alemão, o kindergarten vem dessa brincadeira de que as crianças seriam as plantinhas que estão sendo preparadas. [...] Assim, infelizmente, na nossa educação, não só daqui, mas de muitos lugares, acontece essa ruptura e isso acaba representando uma perda para a criatividade. (informação verbal) ${ }^{3}$.

Após uma explanação de como o ensino deve se adaptar aos novos tempos, Hofmann, em seu Manual de design gráfico, enumera seis passos a serem adotados: (1) cada nível do ensino deve ter uma distinção clara, mas sem impedir a continuidade do aprendizado; (2) a educação deve estar em constante atualização; (3) não há distinção entre trabalho experimental livre e trabalho encomendado. Todo exercício deve apresentar um resultado e cada resultado final deve expressar aspectos que demonstrem um escopo de exercícios e experimentos. Esse ponto dialoga com o que Leopoldo Leal entende sobre a importância de seguir um processo criativo experimental, mas sem esquecer do valor do resultado do resultado:

O processo é importantíssimo, mas, é claro, para chegar em algumas coisas que sejam sofisticadas, interessantes. Você não pode falar que o processo é importante e o seu resultado ser igual ao de todo mundo - então o processo não foi importante. Um resultado sem um processo é algo fraco, mas um processo sem resultado razoável também é muito gratuito. (informação verbal) ${ }^{4}$.

Os próximos pontos: (4) não distinguir o trabalho artístico do trabalho comercial e procurar uma unidade válida entre as duas esferas; (5) não deve haver separação entre "[...] trabalho espontâneo com um tom emocional e trabalho dirigido pelo intelecto. [...] Disciplina e liberdade devem, portanto, ser vistas como elementos de igual peso, um participando do outro [...]"; (6) repensar a relação de interdependência entre design e meios de reprodução (HOFMANN, A., 2015, p. 40).

\footnotetext{
${ }^{2}$ Entrevista concedida por LEAL, Leopoldo. Leopoldo Leal: depoimento [jul. 2020]. Entrevistadora: Alice Viggiani. São Paulo, 2020. 1 vídeo .mp4 (127 min.).

${ }^{3}$ Ibid.

${ }^{4}$ Ibid.
} 


\section{Armin Hofmann e a prática projetual}

Quanto menos trabalho experimental realizado por pessoas envolvidas na prática real de uma profissão e com a intenção de extrair dela o máximo de ganhos materiais possível, mais energia e cuidado as escolas devem dedicar ao experimento e à pesquisa.

(HOFMANN, A., 2015, p. 39).

Na passagem, fica clara a defesa de Hofmann em aliar a vida profissional de um designer aos conhecimentos adquiridos em experimentos didáticos. No mesmo ano em que o professor começa a lecionar na Basileia (1947), abre também um ateliê de design em conjunto com sua esposa Dorothea. As duas atividades, ensino e prática projetual, vão lhe acompanhar por toda a sua trajetória. Essa busca por unir partes aparentemente dissonantes é notada também por Philip Meggs e Alston Purvis, mas pelo enfoque formal de seu trabalho:

Em seu trabalho e ensino, Hofmann continua a buscar uma harmonia dinâmica, em que todas as partes de um projeto são unificadas. Ele vê a relação entre elementos contrastantes como meio de revigorar o projeto visual. Esses contrastes abrangem luz e sombra, linhas curvas e linhas retas, forma e contraforma, macio e áspero, dinâmico e estático, sendo que a resolução é alcançada quando o designer leva o conjunto a uma harmonia absoluta.

(MEGGS; PURVIS, 2009, p. 472).

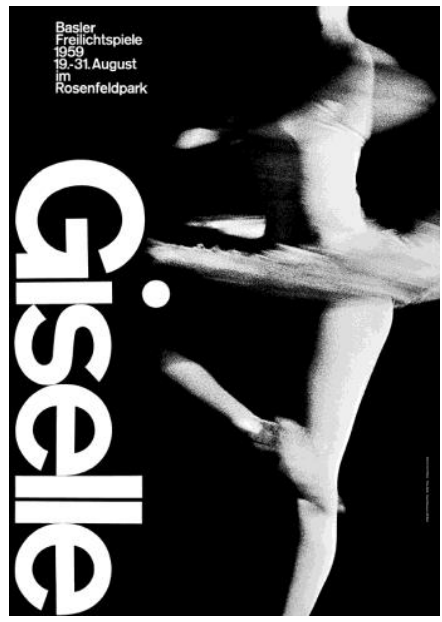

Figura 1: Cartaz para o espetáculo Giselle, do Basler Freilichtspiele (1959). Fonte: Imagem cedida e autorizada por () Matthias Hofmann.

Richard Hollis considera Hofmann como responsável pela "[...] criação de centenas de bons logotipos e marcas suíças [...]" (HOLLIS, 2006, p. 144). Mas são os cartazes, principalmente aqueles dedicados às instituições culturais e das artes, que representam seu maior legado. Sobre o de Giselle, de 1959 (Figura 1), Hollis analisa: "Cada elemento contribui para sua dramática elegância [...]. A bailarina, cortada na cabeça e nos pés, é transformada em um sinal gráfico de movimento [...]" (HOLLIS, 2006, p. 127). Outra obra emblemática é o cartaz Das Holz als Bau Stoff [A madeira como material de construção], de 1952 (Figura 2). Dorothea Hofmann menciona o cartaz para exemplificar o pensamento da Basileia:

O tipo e a forma do desenho escolhidos foram desenvolvidos especificamente a partir do tema subjacente e ilustram o estilo dos edifícios com estrutura de madeira suíça [...]. Mesmo que o cartaz Das Holz als Bau Stoff pareça à primeira vista um excelente exemplo do design de direção concreto-construtiva, era na realidade a expressão de um estilo intuitivo, rigoroso, mas muito claro e preciso, de caráter e escrita, baseado na elementar 
teoria do design pragmático. Uma doutrina que está inteiramente na tradição de Ernst Keller, que representou a convicção de que o design se desenvolve a partir do conteúdo e não tem de seguir um certo estilo. (HOFMANN, D., 2016, p. 12).

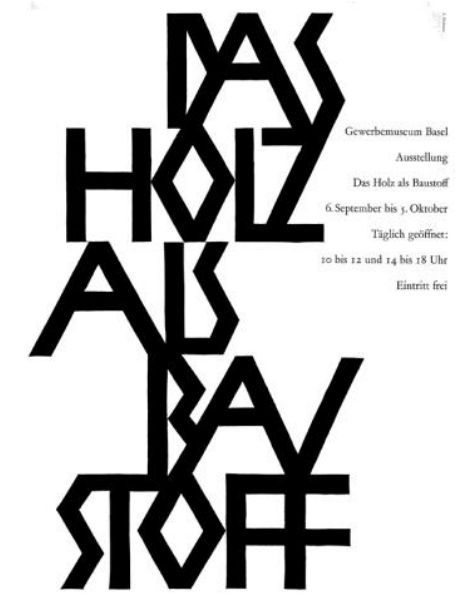

Figura 2: Cartaz de divulgação Das Holz als Bau Stoff (1952). Fonte: Imagem cedida e autorizada por () Matthias Hofmann.

\section{Projetar é formular (e resolver) problemas}

Armin Hofmann entende o ofício como um problema a ser resolvido gráfica e visualmente. No prefácio de seu manual, George Nelson observa: "Ele chega naturalmente à convicção de que, se os problemas puderem ser corretamente declarados, eles poderão ser resolvidos." (NELSON, 2015, p. 35). Aqui, mais uma vez, Leopoldo Leal alinha-se à visão projetual de Hofmann. Em seu doutorado, define "problema" como "[...] tudo aquilo que não tem uma resposta imediata a partir de um conhecimento preexistente. Aparece quando é necessário fazer uma escolha dentro de algumas possibilidades." (LEAL, 2019, p. 23).

\section{A prática projetual no Manual de design gráfico}

Suas ideias, estabelecidas em Manual de design gráfico: princípios e prática, publicado pela primeira vez em 1965, foram introduzidas em escolas de design em todo o mundo [...] (HOLLIS, 2006, p. 215).

Em 1965, passados quase vinte anos de professorado na Escola da Basileia, Armin Hofmann sistematiza todo o seu conhecimento na obra-síntese Manual de design gráfico: princípios $e$ prática. O livro, dividido em quatro capítulos principais - "O ponto", "A linha", "Confronto" e "Letras e sinais"-, expõe inúmeros exemplos de exercícios teóricos realizados ao longo dos anos, intercalados, sem nenhuma distinção, com trabalhos profissionais finalizados, como cartazes, anúncios, símbolos e logotipos. Se Hofmann sempre aliou a prática profissional ao ensino, em seu Manual de design gráfico isso fica ainda mais explícito. Sua obra "[...] fornece fácil acesso aos problemas educacionais do design visual [...]" (HOFMANN, A., 2015, p. 36).

Fazem parte do manual de Armin Hofmann experimentos como passar um crayon sobre um papel disposto sobre uma superfície rugosa e extrair uma textura, criando uma padronagem 
resultante do experimento físico. Ao mesmo tempo que Hofmann sente a necessidade de escrever um manual de design gráfico - o que é uma recorrência entre os cânones do design gráfico moderno -, ele também incentiva aí a possibilidade de experimentações livres e invenções ao propor exercícios que envolviam a imprevisibilidade do resultado. E são justamente esses experimentos, associados a noções matemáticas de composição, que Hofmann entende por design gráfico. Leopoldo Leal elimina o aspecto conotativo da palavra "manual" e localiza o documento dentro do movimento moderno de design gráfico:

Não só o livro dele, como os de outros, de [Wolfgang] Weingart e [Josef Müller-] Brockmann, todos esses usam a palavra "manual", que acaba sendo malvista. Mas a palavra que eles utilizam é para explicar que ali estão compreendidos conhecimentos sobre técnicas e processos em design gráfico. Para mim, são fontes inesgotáveis de conhecimento para a área. E algo que é muito valioso, porque é muito claro o que eles expressam: a importância de você formular um problema. (informação verbal) ${ }^{5}$.

\section{Categorias}

Para uma melhor compreensão dos exercícios que foram expostos no Manual de design gráfico, foram realizadas uma análise e uma catalogação de acordo com similaridades entres as imagens, tanto do ponto de vista formal como do ponto de vista do processo criativo e do contexto de cada trabalho (Quadro 1). Em termos de processo de criação, os exercícios foram divididos entre aqueles construídos por meio de gráficos, com instrumentos de desenho, e aqueles que partem de experimentos físicos (legendados no manual sob o termo "transposição para a natureza"). Os exercícios gráficos foram subdivididos em: "Padronagem", nos quais o elemento central é um grid; "Composição", em que se valoriza como os elementos devem se dispor no conjunto; "Variação", em que se explora o que, de um mesmo elemento, poderia ser alternado; além dos grupos "Textura", "Figurativo" e "Tipografia". Para os experimentos físicos, aparecem novamente os grupos "Textura", "Figurativo" e "Tipografia", aos quais somam-se "Fotografia" e "Volumetria".

\footnotetext{
${ }^{5}$ Entrevista concedida por LEAL, Leopoldo. Leopoldo Leal: depoimento [jul. 2020]. Entrevistadora: Alice Viggiani. São Paulo, 2020. 1 vídeo .mp4 (127 min.).
} 





Olhando para a natureza de cada exercício, as páginas foram agrupadas em "Exercício didático", "Trabalho profissional finalizado" e "Ensaio para trabalho profissional", que foi ainda subdividido em "Embalagem" e "Impresso". Cada página de exercícios pode conter mais do que uma categoria em sua proposição, mas a catalogação levou em conta o que foi mais sobressalente em cada caso. Observando o quadro, nota-se que os trabalhos profissionais se concentram nas categorias de elementos concretos, como os figurativos, os tipográficos e os que fazem uso da fotografia, enquanto as categorias de elementos mais fundamentais do desenho, como composição e variação, são reservadas prioritariamente para os exercícios formais livres. De toda forma, vários dos experimentos propostos são apreendidos e ressurgem como ideia nos trabalhos encomendados.

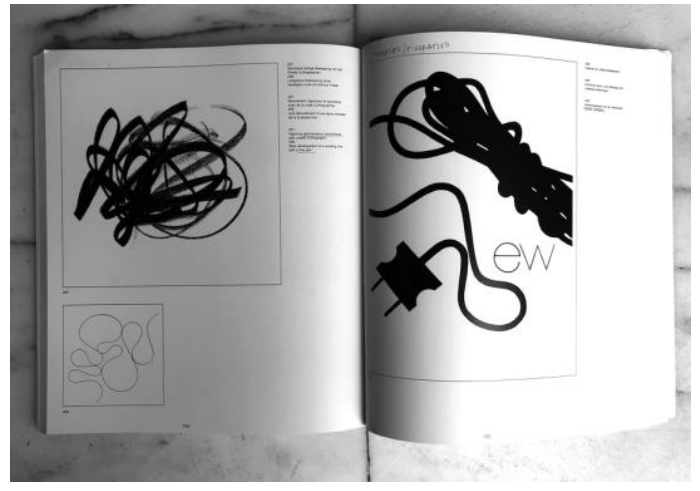

Figura 3: Reprodução das páginas 154-155 do Manual de design gráfico (1965/2015), de Armin Hofmann. Fonte: Hofmann (2015); foto de Alice Viggiani. Reprodução autorizada pela editora Niggli.

O primeiro exercício do livro, dentro do capítulo "O ponto", é um experimento físico. $\mathrm{Na}$ página seguinte, contudo, já se vê um exercício a partir de um grid geométrico, uma construção artificial. A Figura 3 também demonstra essa noção de dualidade em Hofmann: a partir de testes realizados com movimentos espontâneos e vigorosos com crayon, essa mesma ideia de textura é depois utilizada em um anúncio para uma companhia elétrica. Outro exemplo o que se vê na Figura 4: enquanto a primeira página mostra um exercício de composição livre, com linhas dentro de um grid ortogonal e diagonal, na página seguinte vemos um logo criado para a empresa de construção de aço Suter, utilizando claramente os conhecimentos adquiridos no exercício além de um aspecto de insinuação figurativa e tipográfica.

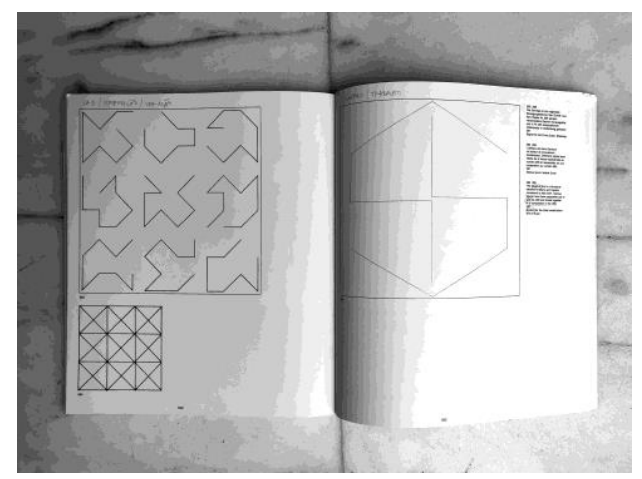

Figura 3: Reprodução das páginas 182-183 do Manual de design gráfico (1965/2015), de Armin Hofmann. Fonte: Hofmann (2015); foto de Alice Viggiani. Reprodução autorizada pela editora Niggli. 
Hofmann não credita os alunos que realizaram cada um dos exercícios. Nem mesmo nos trabalhos profissionais é explicitado se são de sua autoria (como alguns sabidamente são) ou se pertencem a estudantes também. A única menção feita sobre isso é na ficha técnica do livro, em que consta: "Reproduções de estudos executados no Curso Gráfico (Fachklasse) da AGS, Basileia." (HOFMANN, A., 2015, p. 5). Contudo, no livro de sua esposa Dorothea Hofmann, é possível encontrar legendas com nomes dos então estudantes que executaram alguns desses exercícios. A designer Thérèse Moll, por exemplo, assina o trabalho Zehn Teile eines Balkenrasters in Bewegung [Dez partes de uma grelha de vigas em movimento], de 1950, exposto na página 118 do manual (HOFMANN, D., 2016, p. 207). Colega de classe de Dorothea Hofmann, Moll foi descrita por Elizabeth Resnick como "[...] uma estudante exemplar. Como evidenciado por seu trabalho, tinha inclinação pela técnica, era focada nos detalhes e dedicada.” (RESNICK, 2019).

Outra fonte que credita aos estudantes alguns dos exercícios expostos no manual de Hofmann é a exposição Armin Hofmann - The Pedagogical Dimension [Armin Hofmann A dimensão pedagógica], de 2020, organizada pela Escola de Design da Basileia em parceria com a FHNW Academy of Art and Design e a Alliance Graphique Internationale (AGI). O designer gráfico Manfred Maier, por exemplo, assina o trabalho Nature Study Point and Line [Estudo da natureza, ponto e linha], de 1963, registrado em preto e branco na página 63 do manual. Anos mais tarde, em 1977, Maier publica o livro Basic Principles of Design: The Foundation Program at the School of Design Basel, Switzerland [Princípios básicos do design: o programa de fundação da Escola de Design da Basileia].

\section{Basileia, a prática projetual, o manual e o Brasil de hoje}

Por ter como principal objeto de investigação os elementos fundamentais da composição visual, Armin Hofmann deixou uma produção e um legado de ensino que atravessam o tempo. Diante das novas formas mecânicas de produção, o designer reafirma sua linguagem: "Devemos voltar ao começo, nos preocupar com pontos, círculos e linhas e todo o resto." (HOFMANN, A., 2015, p. 35). Leopoldo Leal, ao olhar para as suas principais referências dentro do campo do design, localiza o moderno e o pós-moderno na linha do tempo para refletir que, se o pós-moderno dos anos 1980 representou uma grande moda, depois de certo tempo, vê que "[...] esses trabalhos ficaram datados e os trabalhos que a gente vê lá de trás, dos anos 1960, mantém o frescor até hoje. Então a ideia é trazer um pouco do que é o pós-moderno, que é um experimento por si só, mas um experimento sem esse rigor acaba ficando um pouco solto demais." (informação verbal) ${ }^{6}$.

\footnotetext{
${ }^{6}$ Entrevista concedida por LEAL, Leopoldo. Leopoldo Leal: depoimento [jul. 2020]. Entrevistadora: Alice Viggiani. São Paulo, 2020. 1 vídeo .mp4 (127 min.).
} 
Armin Hofmann em Pandemonium e em linguagem de programação

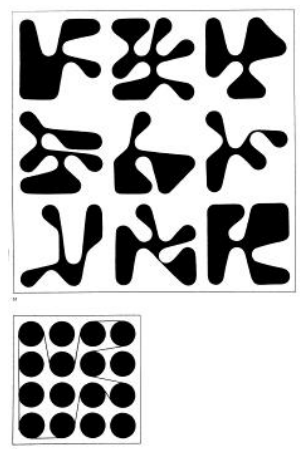

Figura 5: Reprodução dos exercícios da página 70 do Manual de design gráfico, gráfico (1965/2015), de Armin Hofmann. Fonte: Hofmann (2015). Reprodução autorizada pela editora Niggli.

Leopoldo Leal, em sua tese Pandemonium, defendida em 2019 e ganhadora do $33^{\circ}$ Prêmio Design MCB, sustenta que não temos um pensamento linear ao desenvolver um projeto; pelo contrário, o processo criativo sempre partirá de um conjunto de elementos dispostos caoticamente na mente do designer. "O processo criativo constitui-se conforme o projeto se desenvolve, havendo sempre desvios, erros, improvisações e surpresas que ajudam a construí-lo.” (LEAL, 2019, p. 5).

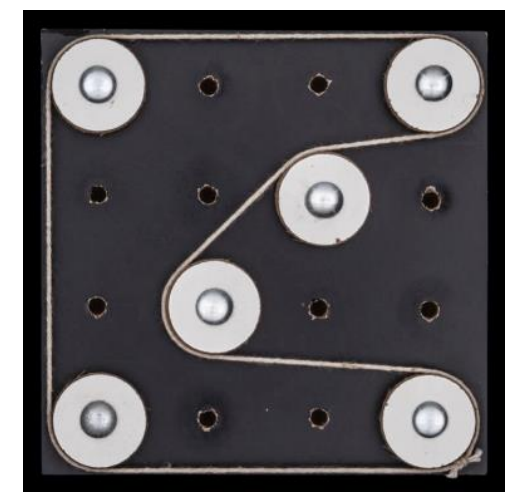

Figura 6: Fotografia extraída da página 235 de Pandemonium (2009), tese de doutorado de Leopoldo Leal. Fonte: Leal (2019). Reprodução autorizada pelo autor.

Em um dos experimentos visuais apresentados em sua tese (Figura 6), Leal parte de um exercício proposto por Armin Hofmann em seu manual (Figura 5). "A partir de poucos elementos chega-se a resultados inusitados, como um jogo divertido e disciplinado, em que novas oportunidades são apresentadas para serem possivelmente trilhadas.” (LEAL, 2019, p. 19). Segundo o autor, "[...] o exercício de Armin Hofmann chamou atenção pela simplicidade, pelo modo como há várias possibilidades ali de gerar formas. E também pela universalidade, quando o exercício tem algo como um jogo, com regras claras e instigantes. E isso, para mim, é universal.” (informação verbal) ${ }^{7}$.

\footnotetext{
${ }^{7}$ Entrevista concedida por LEAL, Leopoldo. Leopoldo Leal: depoimento [jul. 2020]. Entrevistadora: Alice Viggiani. São Paulo, 2020. 1 vídeo .mp4 (127 min.).
} 


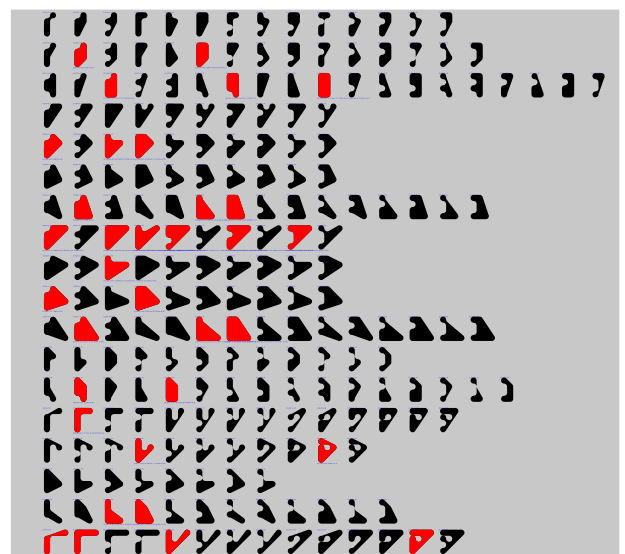

Figura 7: Captura de tela do aplicativo desenvolvido por Leopoldo Leal e Alexandre Villares rodando em Processing. Fonte: Imagem cedida por Leopoldo Leal e Alexandre Villares.

Posteriormente à apresentação de sua tese, o pesquisador, em conjunto com o artista visual e educador Alexandre Villares, desenvolveram alguns ensaios para um aplicativo em Processing (Figura 7) que possibilitava gerar as formas inicialmente propostas pelo jogo de Leal, inspirado, por sua vez, no exercício didático de Hofmann.

Partindo de um tabuleiro com um grid de 4x4 pinos, Villares conta que, com o auxílio da programação, é possível calcular e executar todas as permutações e combinações existentes dessas formas poligonais com base em diretrizes estabelecidas previamente. Além disso, uma vez construído o aplicativo, é possível testar novas regras ou novas condições para a geração de tais formas. Os pesquisadores testaram quatro variações para a dimensão desses pinos, do vértice mais arredondado, de maior diâmetro de circunferência, até um vértice mais afiado, de menor diâmetro. $\mathrm{O}$ aplicativo demonstrou que o número de possibilidades é modificado para cada variação (informação verbal) ${ }^{8}$.

Dessa forma, cada variação permitiu um grande número de exemplares (que se diferenciam pelo posicionamento dos pinos no tabuleiro). Os resultados da pesquisa até o momento indicam uma ordem de grandeza de 160 mil possibilidades no total, sendo algo em torno de 25 mil formas a variação de menor diâmetro, com o menor número de possibilidades, e cerca de 60 mil formas para a variação de maior dimensão do pino. Essas observações se tornam mais plausíveis a partir de uma ferramenta computacional. De fato, mesmo que Hofmann tenha concebido programaticamente seu exercício original, dificilmente conseguiria executar todas as possibilidades para cada novo conjunto de diretrizes.

Sem um computador, não conseguiríamos chegar em todas as possibilidades, mas sem a ideia, sem as regras, o computador também não chega. Com o digital, com a possibilidade que nós temos nessa linguagem, ele proporciona a geração quantitativa das coisas. Vejo que outro ponto necessário é o entendimento do que foi gerado. (informação verbal) ${ }^{9}$.

Villares também presta um depoimento semelhante. Aos ser questionado sobre o projeto, comenta que já estava pesquisando algo no mesmo sentido do jogo proposto em Pandemonium, que envolvia gerar formas com tangência, com continuidade, sem, contudo, fazer referência

\footnotetext{
8 Entrevista concedida por VILLARES, Alexandre. Alexandre Villares: depoimento [jul. 2020]. Entrevistadora: Alice Viggiani. São Paulo, 2020. 1 vídeo .mp4 (100 min.).

${ }^{9}$ Entrevista concedida por LEAL, Leopoldo. Leopoldo Leal: depoimento [jul. 2020]. Entrevistadora: Alice Viggiani. São Paulo, 2020. 1 vídeo .mp4 (127 min.).
} 
direta, ou até mesmo ser influenciado, pelo exercício de Hofmann (informação verbal) ${ }^{10}$. De toda forma, a adaptação do que já vinha investigando para o jogo proposto por Leal não foi difícil, já que eram próximos os princípios ali colocados.

Ter Armin Hofmann como ponto de partida é, evidentemente, demonstrar sua influência até os dias de hoje. Porém, essa não é a única indicação dos ecos da geração de Hofmann sobre o pensamento projetual e a prática de ensino em design no Brasil. A entrevista com Leopoldo Leal marcou um diálogo constante com a trajetória de Hofmann aqui descrita. Do mesmo modo, é notória a consonância com os princípios gerativos descritos por Alexandre Villares em seu depoimento, sobretudo em relação aos princípios de criação, mas também ao pensamento do ensino, considerando o que é colocado hoje pelos educadores contemporâneos e as preocupações de Armin Hofmann nas décadas de 1940 a 1960.

\section{A indústria, o computador e a criação do padrão}

A escola deve se opor vigorosamente à visão de que, dado o equipamento técnico moderno adequado, é possível viver em uma organização que funcione perfeitamente, sem nenhum esforço ou contribuição pessoal (HOFMANN, A., 2015, p. 38).

Na passagem, o designer suíço reflete sobre os novos meios de produção e mecanização em pleno processo de industrialização, no contexto do pós-guerra europeu. Dado o cenário, é notório como existem especulações acerca de um futuro incerto. Nesse sentindo, Hofmann aponta receios, mas também perspectivas possíveis para o ofício do designer gráfico. "Uma indústria de papeis que se propõe a préfabricar todos os tons de cor fará da mistura de cores uma coisa do passado." (HOFMANN, A., 2015, p. 39). Como garantir que o designer da nova geração não se afaste do conhecimento de composição das cores? Leal também reflete sobre o significado da padronização da indústria:

Quando a indústria padroniza as coisas, a gente perde esse sentido de "experimentar" e fica reduzido ao que a indústria nos oferece, porque acha que só existem aquelas cores. No computador, a mesma coisa. Se você ficar preso ao que já está pronto nele, fica reduzido só àquelas respostas. É interessante se valer dele como ferramenta, não como resposta. Aqueles que usam uma ferramenta de maneira padrão oferecem respostas formais muito similares àquelas que todos os outros que estão usando a mesma ferramenta chegam (informação verbal) ${ }^{11}$.

\section{O movimento moderno e o Brasil}

"Encontrar o componente humano nesse novo horizonte e clima é o problema que devemos todos confrontar." (NELSON, 2015, p. 35). É assim que George Nelson apresenta o manual de Armin Hofmann, elaborando as novas formas de trabalho tanto dos meios de produção como da organização do trabalho, além de considerar como esses fatores se refletem na linguagem visual. Nesse sentido, procurando responder o porquê de o design moderno ter

10 Entrevista concedida por VILLARES, Alexandre. Alexandre Villares: depoimento [jul. 2020]. Entrevistadora: Alice Viggiani. São Paulo, 2020. 1 vídeo .mp4 (100 min.).

${ }^{11}$ Entrevista concedida por LEAL, Leopoldo. Leopoldo Leal: depoimento [jul. 2020].

Entrevistadora: Alice Viggiani. São Paulo, 2020. 1 vídeo .mp4 (127 min.). 
sido tão bem aceito e adotado como linguagem hegemônica no Brasil a partir da década de 1960, Leal levanta sua hipótese.

Em primeiro lugar, pontua que a linguagem moderna chega não só no Brasil, mas em vários países da América Latina, como Argentina, Venezuela e Uruguai. Diferente da Bolívia e do Peru, que possuem uma herança gráfica nativa sofisticada, os países que absorveram mais amplamente tal linguagem geométrica, como o Brasil, não estiveram conectados de forma tão proeminente com a cultura visual dos povos indígenas que originalmente habitavam o território. Contudo, Leal pontua que dessa contradição "[...] nasce um estilo moderno que é mais brasileiro, mais tropical, inevitavelmente. A gente vê que existe uma diferença entre o que é feito aqui e o que é feito na Suíça.”. Para demonstrar, cita exemplos: "O Aloísio Magalhães, o Ruben Martins, vemos que usavam uma gramática moderna, mas o trabalho tem um frescor, uma conexão com a realidade latina, brasileira." (informação verbal) ${ }^{12}$.

\section{Ensino de design hoje no Brasil}

Leopoldo Leal é contundente ao afirmar "[...] que a falta de autonomia é uma grande dificuldade dos alunos.". Tendo a experiência de já ter lecionado para diversas faixas etárias, desde crianças com quatro anos de idade até estudantes de pós-graduação, nota que, "[...] depois que houve esse esquema de ensino 'professor manda', quando eles chegam na graduação, a grande maioria tem problemas para entender que o projeto, a educação, é deles.”. Por outro lado, “[...] aqueles que conseguem fazer essa virada da autonomia, entender que 'sou eu que comando o projeto', esses têm uma virada muito boa.”. Dessa forma, segundo Leal, o maior desafio de um educador seria o de fazer com que os alunos resgatem essa autonomia perdida e, mais, que eles consigam se sensibilizar com o projeto e com o "[...] sentir o mundo, o pegar nas coisas [...]" (informação verbal) ${ }^{13}$.

Essa preocupação de Leal também mostra ecos diretos às proposições de Hofmann quando este sugere experimentos que envolvam o meio físico e sua materialidade sensorial: o asfalto, a folha da planta, o movimento gerado pela câmera ao fotografar uma tipografia. Contudo, no Brasil, como observa Leal, existe outro agravante que pode afastar ainda mais o ensino formal da incorporação dos experimentos físicos: "Existe no Brasil um problema grande sobre isso, porque, dentro da formação da nossa sociedade, aquelas pessoas que pegam nas coisas, que pegam no mundo, são vistas como inferiores, infelizmente. Então muitos alunos de design acabam não querendo fazer tarefas manuais, por acharem algo inferior." (informação verbal) ${ }^{14}$.

\footnotetext{
${ }^{12}$ Entrevista concedida por LEAL, Leopoldo. Leopoldo Leal: depoimento [jul. 2020]. Entrevistadora: Alice Viggiani. São Paulo, 2020. 1 vídeo .mp4 (127 min.).

13 Ibid.

${ }^{14}$ Ibid.
} 


\section{Conclusão}

É notória em Armin Hofmann sua constante busca pelo equilíbrio entre partes aparentemente antagônicas: seja entre trabalho artístico e comercial, espontaneidade e planejamento, trabalho profissional e exercício didático, atuação prática e ensino de design. O mergulho nos exercícios propostos pelo designer ao longo de sua carreira como professor de desenho permitiu que se percebesse sensivelmente o que já havia sido colocado verbalmente em outros momentos. Essa análise, somada ao relato da ex-aluna Dorothea Hofmann e ao depoimento prestado pelo professor e designer gráfico Leopoldo Leal, nos permitiu enxergar que Hofmann opera a todo momento por binômios ora antagônicos, ora díspares. Isso tanto no âmbito do trabalho em si, formalmente falando, entre o não controlado e o planejado, como na natureza do processo criativo, entre matemática e inventividade, ou até mesmo em sua trajetória de vida, como profissional e professor.

A maior das dicotomias talvez seja o fato de seu trabalho ser, ao mesmo tempo, diretivo e experimental. Mais do que os métodos em si, podemos guardar como lição o princípio, seguido pela prática, da desenvoltura na busca pelo desconhecido, que se associa ao apreço pelo rigor construtivo e pela beleza estrutural. Foi Leal quem escreveu, mas poderia ter sido o designer moderno: "Inspiração é fruto de trabalho, não o contrário." (LEAL, 2019, p. 18).

O presente trabalho foi realizado com apoio da Coordenação de Aperfeiçoamento de Pessoal de Nível Superior - Brasil (CAPES) - Código de Financiamento 001.

\section{Referências}

GREIMAN, April. Interview: April Greiman. [Entrevista cedida] a Louise Paradis. In: PARADIS, L. et al. TM RSI SGM 1960-90: Research Archive. Los Angeles, ago. 2010. Disponível em: http://www.tm-research-archive.ch/interviews/april-greiman.

Acesso em: 25 nov. 2020.

HOFMANN, Armin. Graphic Design Manual: Principles and Practice. Zurich: Niggli, 2015.

HOFMANN, Dorothea. Die Geburt eines Stils: Der Eifluss des Basler Ausbildungsmodells auf die Schweizer Grafik. Zürich: Triest, 2016.

HOLLIS, Richard. Swiss Graphic Design. New Haven: Yale University Press, 2006.

LEAL, Leopoldo Augusto. Pandemonium: processo criativo, experimentação e acaso. Tese (Doutorado em Design e Arquitetura) - Faculdade de Arquitetura e Urbanismo da Universidade de São Paulo, São Paulo, 2019.

MEGGS, Philip B.; PURVIS, Alston W. História do design gráfico. São Paulo: Cosac Naify, 2009.

NELSON, George. Preface. In: HOFMANN, Armin. Graphic Design Manual: Principles and Practice. Zurich: Niggli, 2015. p. 35-36. 
RESNICK, Elizabeth. The enigma of Thérèse Moll. Eye, London, v. 25, n. 98, 2019. Disponível em: http://www.eyemagazine.com/feature/article/the-enigma-of-therese-moll. Acesso em: 25 nov. 2020.

TRIEST VERLAG. Origin and dissemination of Swiss Graphic Design. In: TRIEST VERLAG. Triest. Zurich, nov. 2016. Disponível em: https://www.triestverlag.ch/files/items/2882/WZ_Hofmann_Geburt_eines_Stils_EN.pdf. Acesso em: 25 nov. 2020.

\section{Sobre as autoras}

Alice Viggiani é designer gráfica formada em Arquitetura e Urbanismo pela FAU USP. Com foco nas estruturas formais, atualmente desenvolve pela mesma instituição sua pesquisa de mestrado em design, investigando quais aspectos da produção atual do design digital foram antecipados pela escola moderna de design gráfico. Atua profissionalmente desde 2010, tendo já trabalhado no Estúdio Lógos, Masp, revista Bamboo, entre outros.

ORCID: orcid.org/0000-0003-1069-3093

Clice Mazzilli é professora associada do Departamento de Projeto da FAU USP, onde realizou seu mestrado, doutorado e livre docência. Atualmente coordena o Programa de Pós-graduação em Design e é vice-coordenadora do Laboratório de Pesquisa em Design Visual. Reúne experiência nos seguintes temas: linguagem visual gráfica; design editorial; design ambiental; processos experimentais; processos de criação; interfaces entre design; arte e arquitetura.

ORCID: orcid.org/0000-0002-6903-9099 